\title{
Editorial: Handing over the baton
}

\section{Farewell editorial}

This issue is my last one after four exciting years as editor-in-chief of Fennia. I have been working within the limits of the reduced resources that a small journal like Fennia can have, but with totally free hands, not least because the journal is entirely autonomous and not managed by any publishing house. The principles of independence from corporate publishers and free (non-fee based) open access have been strongly supported by the Geographical Society of Finland, and I have fully endorsed them, even when they have produced heavier workload on the small editorial team. In fact, the entire journal production process, online archiving (including old issues) as well as promotion, are under the joint responsibility and operation of the editor and the manager. We have even internalized the layout work previously done by an external unit.

Therefore, I sincerely thank the two editorial managers I have had the pleasure to work with: Helka Kalliomäki until 2014, and then Hanna Salo. Their work is highly professional, though symbolically rewarded, and their competence and commitment have to be fully acknowledged. Together, we have introduced some basic improvements in the editorial and proofreading process, and in the journal website. Examples are the adoption of cross reference and digital object identifier (DOI) numbers supporting citations; the formation of an archive area of old issues, and of another area containing forthcoming articles, which can be accessed before the full issue is published.

Also, I would like to thank the Geographical Society, the two presidents who have believed in our journal's strengthening project, and the secretary of the Society Maija Taka who has closely cooperated with me, being so helpful in raising funds for training and travels and linking us with the Society members and other academic bodies. Then I would like to recognize the important contribution of the colleagues involved in the editorial advisory board, accepting reviewing tasks, proposing theme issues and giving various sorts of advice. The board of Fennia has become truly international, highly experienced in scientific publishing, and with diverse expertise in many geographical fields. This variety of focus is reflected in the multi-thematic issues containing articles in both physical and human geography, reporting work that uses both quantitative and qualitative methods, and also hosting critical scholarship. Some of the topics in human geography were for instance on migration and multi-ethnic identities, tourism, borders and relations with Russia, academic capitalism, cultural landscapes, gender and queer theory, gentrification, development, and ethnography.

All in all, I am satisfied with the important achievements we have reached in these four years, raising international attention, readership, number of submitted papers and overall academic quality. The journal has gained reputation and is now indexed in Scopus, Thomson Reuters Emerging Sources Citation Index (ESCl) and in the Directory of Open Access Journals (DOAJ). Moreover, the recognition of ethics performances in peer-reviewing is recognized and certified by the labels of by the Federation of Finnish Learned Societies (TSV) and, internationally, by the Committee on Publication Ethics (COPE).

For this, I am delighted that the journal has gone in excellent hands, those of Kirsi Pauliina Kallio, who has already a lot of expertise and will continue along the same project, with renewed energy, to further strengthening the journal's positioning within the Nordic publishing domain and beyond. I wish Kirsi all the best for this important work.

Paola Minoia, University of Helsinki, Finland. Email: paola.minoia@helsinki.fi

\section{Salute editorial}

This is the first issue of Fennia where I am involved as an editor, or perhaps more rightly as the editorto-be, as I joined the editorial team early this year. Most papers included in this issue were already firmly in Paola's hands at that time and they have been finalized under her skilled editorship, which has made it easy for me to start learning more about this journal and my post as its editor-in-chief during the past months. My sincere thanks to Paola and Hanna for the smooth start. 
I also wish to present my gratitude to the Geographical Society of Finland for inviting me to this position. As the scope of the journal covers all existing, forthcoming and imaginable human and physical geographical research my competence can be nothing but partial. Yet I promise to try my best, to offer high quality publication processes to all scholars who wish to introduce their work to the scientific community through Fennia, and thus, continue the journal's revival. This challenge seems feasible by the help of the editorial board that has agreed on working with me in the coming years - together we 25 geographers will make it fly! I am particularly happy about the broad geographical scope of the board that reflects rightly the agenda of the journal; we aim to be a truly international journal that publishes research from all continents and regions, related to any geographically pertinent topic. This said we are particularly happy to receive contributions with northern dimensions.

Our second important agenda is openness. Fennia is committed to an open access publication policy without embargo and author fees. All texts are made publically available right after acceptance, as forthcoming. Our fast publication processes and online format also allow that the forthcoming articles are included in one of the next two issues, released during the following March and September. By these means, we aim to provide an alternative publication channel to journals owned by big publication houses. We hope that geographers will find these opportunities increasingly inviting.

In addition to individual papers, Fennia welcomes special issues on topical themes as well as special sections that we will start publishing as part of regular issues (e.g. polemic debates, author meets critics, interventions). These may be based on conference panels, seminars and other events, which can also be planned in collaboration with the editorial team to ensure a smooth publication process throughout. We are happy to receive suggestions for these and other creative initiatives by which we can enrich the journals content and create dialogical space for geographers and scholars from related fields.

The first initiative I have made as the editor is the establishment of an annual Fennia lecture, to be held at the Finnish Geographers Meeting. The event circulates between six universities where the local geographers organize it in collaboration with the Geographical Society. Our first invited speaker is Professor Henk van Houtum who gives his lecture in Joensuu, at the University of Eastern Finland, in October 272016 . He is an established scholar in border studies, leading the Nijmegen Centre for Border Research at the Radboud University, and holding professorships at the universities of Eastern Finland and Bergamo. Those who are unable to participate the event may read Professor Houtum's lecture in the 2017 March issue where it will be published as the lead article, followed by short commentaries by Finnish geographers.

We want to finish this joined editorial into an invitation. Everyone who believes that scientific knowledge should be freely distributed among all people is warmly welcome to join our efforts in Fennia. Together we can show that alternative publication policies and practices are possible even in this world of citation indexing and research assessment exercises, dominated by commercial publication houses with little genuine interest in scientific progress. Scholars can make a difference by thinking and acting differently.

Kirsi Pauliina Kallio, University of Tampere, Finland. E-mail: kirsipauliina.kallio@uta.fi 